\title{
Article
}

\section{Digital Media: Empowerment and Equality}

\author{
Magdalena Mądra-Sawicka ${ }^{1, *(\mathbb{D})}$, Jeretta Horn Nord ${ }^{2}$, Joanna Paliszkiewicz ${ }^{3}$ (D) and \\ Tzong-Ru Lee ${ }^{4}$ \\ 1 Institute of Economics and Finance, Warsaw University of Life Sciences-SGGW, 02-787 Warsaw, Poland \\ 2 Department of Management Science \& Information Systems, Oklahoma State University, \\ Stillwater, OK 74078, USA; jeretta.nord@okstate.edu \\ 3 Management Institute, Warsaw University of Life Sciences-SGGW, 02-787 Warsaw, Poland; \\ joanna_paliszkiewicz@sggw.edu.pl \\ 4 Department of Marketing, National Chung Hsing University, Taichung City 402, Taiwan; \\ trlee@dragon.nchu.edu.tw \\ * Correspondence: magdalena_madra@sggw.edu.pl; Tel.: +48-225-934-242
}

Received: 13 March 2020; Accepted: 15 April 2020; Published: 18 April 2020

\begin{abstract}
This study investigated the use of digital media, specifically social media technologies, in the workplace in Taiwan. The data for this study were collected through an online survey. Participants responded to questions asking whether social technologies could be a source of empowerment, leading to equality. Respondents included female and male employees. The findings reveal that both genders use social technology platforms for business support, experience benefits, and believe that these technologies could provide empowerment for success. Detailed results are reported in this paper, including a comparative analysis. The differences between women and men using Facebook and YouTube were significant. Women in Taiwan have a higher awareness of the benefits of social technologies, specifically Facebook, when used for business support and empowerment. This paper reveals a comparison between the attitudes of women and men when using social technologies and investigates the realization of the economic empowerment component.
\end{abstract}

Keywords: digital media; empowerment; equality; Taiwan

\section{Introduction}

Digital media platforms have revolutionized how people communicate with each other by excluding socioeconomic, politics, civil disobedience, and connectivity barriers. Furthermore, digital media have brought about rapid changes in the workplace by providing new opportunities [1-4]. In the last decade, digital platforms have allowed organizations to communicate globally, provide customer service, gain exposure and new customers, market products, network, recruit employees, and increase revenues [5]. Digital media increase access to information and human interactivity [6,7].

Social technologies, as a part of digital media, give new opportunities for business support, and have changed the way employees and business owners communicate. These technologies also provide customer service, support gaining exposure and creating awareness about products or companies, acquiring new customers, looking for a new market or brand products and businesses, networking and building relationships or recruitment process of employees. In recent years, researchers have begun to focus on social network service-related issues [8-11]. Facebook, LinkedIn, and other digital platforms have changed everyday life and, more recently, the business environment.

In Taiwan, nearly seven million people are regular social media users [12]. Social media are now a cornerstone of everyday life [13]. Digital media give unique features for connecting with others, which could be beneficial for learning opportunities [14], and it can support the empowerment effects. 
Thus digital platforms support the empowerment of the user; however, it also brings the paradox alignment of freedom and control [15].

The gender gap, female empowerment, and digital media have been widely studied [16-20], yet there is little data on the role of social technologies to empower women and drive economic equality, to eliminate the gender gap of earnings.

Digital technologies have become more and more accessible as tangible tolls for women to overcome inequalities $[3,4,19]$. The usage of social media in different studies underline the high correlation with gender gaps in many different areas of life among all nations [2]. Thus it is essential to investigate the role of social network platforms in business to assess the opportunities for empowerment.

This study - part of an ongoing global study-investigated how social technologies are used in the workplace and whether benefits were experienced with the idea of empowerment for women worldwide. Survey results are revealed regarding the use of technology, the purposes for which social technologies are used, and whether women and men in Taiwan experienced benefits.

The paper aims to check the role of digital media in creating peoples' empowerment and equality. Two research questions are addressed:

(1) Is there a difference in the results for women versus men?

(2) Can social technology platforms provide tools for empowerment?

In the first part of the study concern, the literature review related to the gender gap, empowerment, and digital media is presented. Next, the research results are described. In the end, the conclusions, limitations of the study, and future directions are addressed.

\section{Literature Review}

\subsection{The Gender Gap}

The relationships among personality traits, generalized beliefs, and the use of social media platforms have been studied by several researchers [21-23]. Caison et al. [24] confirmed that there is a significant difference between technology readiness and gender, which is related to different attitudes toward technology [25]. Lin and $\mathrm{Yu}$ [26] also explored gender differences in adolescent Internet usage in Taiwan. The results supported the view that the gap in gender differences in Internet use has decreased in this generation.

In most societies in the world, gender provides a framework for how individuals are expected to behave [27]. Women suffer from discrimination, especially in undeveloped or developing countries, where gender stereotypes exist and where children are taught by adults to behave according to them $[28,29]$. It has been argued that eliminating gender stereotypes will improve access to education, which in turn will help reduce poverty [30,31]. Gender inequalities can also be eliminated by neutralizing cultural biases regarding women [32].

Although the gender gap has decreased with the younger generation, middle-aged and older women represent the lowest usage rate of information and communication technology (ICT) in Taiwan. The Taiwan Women Up (TWU) program has helped such groups to successfully learn ICT skills with the support of members of nonprofit organizations [33]. These groups are a testament to the concern that those governing Taiwan have shown regarding technology and economic gender gaps.

Globally, a gender pay gap exists, and Taiwan is no exception. Taiwan's Ministry of Labor indicated that in 2016 women made $14.6 \%$ less than their male counterparts. The gap has slowly improved since 2002 and has been narrowing over the past decade [34]. To put this in perspective, the Global Gender Gap Index 2020 ranks 153 countries according to how well they are leveraging their female talent pool based on economic, educational, health-based, and political indicators. With a decade of data, this edition of the Global Gender Gap Report-first published in 2006-shows that while the world has made progress overall, stubborn inequalities remain [35]. In the Global Gender Gap Index 2020, there are no Asian countries in the first ten places. Taiwan, an island nation, is not 
included in this particular study, and although inequality exists, a $15 \%$ gender pay gap would put them among the best in this report regarding economic gender equality.

\subsection{Empowerment}

There are many definitions of empowerment in the literature [36]. Empowerment is a process by which powerless people become conscious of their situation, organize collectively to improve it, and access opportunities, as an outcome of which they take control over their own lives, gain skills, and solve problems [37]. According to Kabeer [38], empowerment means expanding people's ability to make strategic life choices, particularly in the context in which this ability had been denied to them. Female empowerment can be defined as a process in which women challenge the existing norms and culture to effectively promote their well-being [36]. According to Wallerstein and Bernstein [39], it is a process that supports the participation of people, organizations, and communities in gaining control over their lives in their community and society. According to several studies [39-41], empowerment is a difficult concept to define and is more easily understood by its absence than its presence.

"Considering that there is a directly proportional relationship between the social and economic status of women and economic growth and development, the improvement of the social and economic statuses of women is imperative, especially in underdeveloped and developing countries. The empowerment of women concerning education, healthcare, labor participation, and political rights will increase the role they will play in growth and development by increasing their contribution to the economy [42]." However, according to Mason and Smith, female empowerment appears to be differently perceived across communities, but it is assessed as more robust when women are better educated and have more opportunities for employment [43]. Hsu [44] indicates that a series of significant transitions have occurred in the past two decades in Taiwan's social and economic structure, changing women's traditional life course, following up with the idea that women's educational opportunities are almost the same as men's in Taiwan.

\subsection{Digital Media}

Social media has become a vital part of digital media. There are many definitions of this term. For example, according to Xie and Stevenson [45], a social media platform is a means of communication through the Internet that enables social interaction. As defined by Kaplan and Haenlein [46] (p. 61), social media are "a group of Internet-based applications that build on the ideological and technological foundations of Web 2.0 and allow the creation and exchange of user-generated content". Steenkamp and Hyde-Clarke [47] defined it as a platform that enables and facilitates information sharing and participation from users of the media to create and distribute the content. Safko and Brake [48] described social media as activities and behaviors among communities of people who gather online to share information and knowledge using conversational media, which makes it possible to create and easily transmit content in the form of words, pictures, videos, and audios.

Social media contains user-generated content that is created through interactions between users. Social media enables the easy creation and sharing of information and entertainment. Social media can take on many different forms, including social network sites, media sharing platforms, and micro-blogs. Social network sites (e.g., Facebook, LinkedIn, or Google+, which was closed on the 2nd of April 2019 for private users) are based on social structures that are made up of a set of individuals and organizations, creating relationships through interaction. Media sharing platforms (e.g., YouTube) enable users to host, upload, manage, and share different multimedia materials (e.g., audio, video, images). Micro-blogging (the most popular site is Twitter) is a broadcast medium that enables the exchange of micro-posts (a small element of content) in the form of short sentences, images, or video links [5].

Social media sites, as web-based platforms, stimulate communication and sharing of information or content between individuals in virtual communities; however, there are privacy concerns [49]. Social media platforms also give a wide range of benefits in many areas. 


\section{Materials and Methods}

\subsection{Instrument and Materials}

A questionnaire was developed to survey women and men in the workplace in Taiwan to investigate how social technologies are used for business support. The survey included sections on demographics, technology, and social technologies. Five different social technology platforms were studied, including Facebook, Twitter, LinkedIn, YouTube, and Google+. Applications and benefits of each platform were identified, with additional questions relating to empowerment and equality. Data were collected electronically from 218 responders, comprising 128 women and 90 men. The study was conducted in 2018 . The participation in the survey was entirely voluntary, and the companies were assured confidentiality and anonymity.

\subsection{Methods}

Quantitative research involves an empirical assessment of numerical measurements, while qualitative methods involve numerical measures. The conducted survey was the primary source of data. Descriptive, $t$-test, Levene's test, and Brown-Forsythe tests were among the statistical analyses conducted on the results. The use of these statistics tools was associated with the verification of the homogeneity of variance when comparing the two research groups-women and men. The Levene's test is useful for equality of variance assessments for variables calculated for two or more groups, using the deviations from the group mean. The Brown-Forsythe test also assesses the equal variance violation, but for this purpose, the test uses the group median.

Using these two tests together gives more definite evidence concerning the variance differences among investigated groups.

\section{Sample}

The average age of the female respondents was 37. Men were slightly older at 41 on average. This average is an indication that not all respondents grew up using social technologies, since most platforms were developed within the last decade.

Over half (53.5\%) of the women surveyed were married, while over two-thirds of the men $(69.6 \%)$ were married. In total, $46.5 \%$ of the women and $57.9 \%$ of the men had children. Although closely divided, the majority of the respondents were in their late 30s to early 40 s and married with children. As revealed in Figure 1, 11.4\% of the responding women owned their own business, while over one-fifth $(22.2 \%)$ of the responding men were business owners-almost double the rate of women. As expected, the vast majority of both women and men worked for someone else.

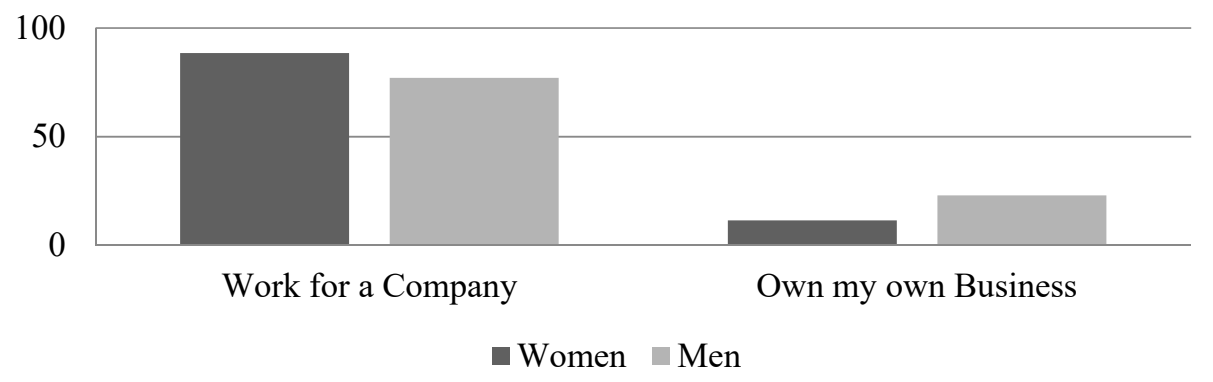

Figure 1. Career.

Figure 2 gives more specific information regarding the organizations in which the respondents work. As noted, over half of the respondents work for corporations. Within this group, more than $60 \%$ of both women and men work in either service or manufacturing. 


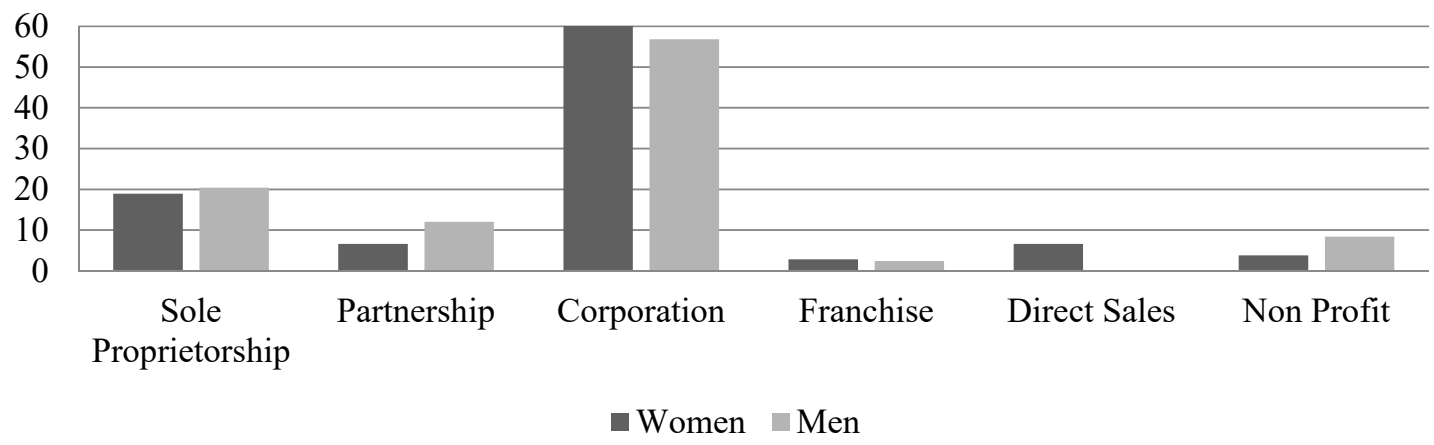

Figure 2. Employment.

\section{Results}

\subsection{Technology}

The focus of this research is on technology, with a closer look at social technologies. Specifically, the use, benefits, and differences between these factors for men and women, and whether opportunities exist for empowerment.

Respondents were asked to indicate devices or technologies that they used. Figure 3 lists the options and percentage of respondents having access by gender. Many reported access to multiple technologies, with the most used device being desktop computers. Significant differences were noticed for the use of laptop computers. Only 39.4\% of the female respondents had access to laptops, while $64.8 \%$ of the men indicated usage of laptop computers. Differences relating to gender for other technologies were minimal.

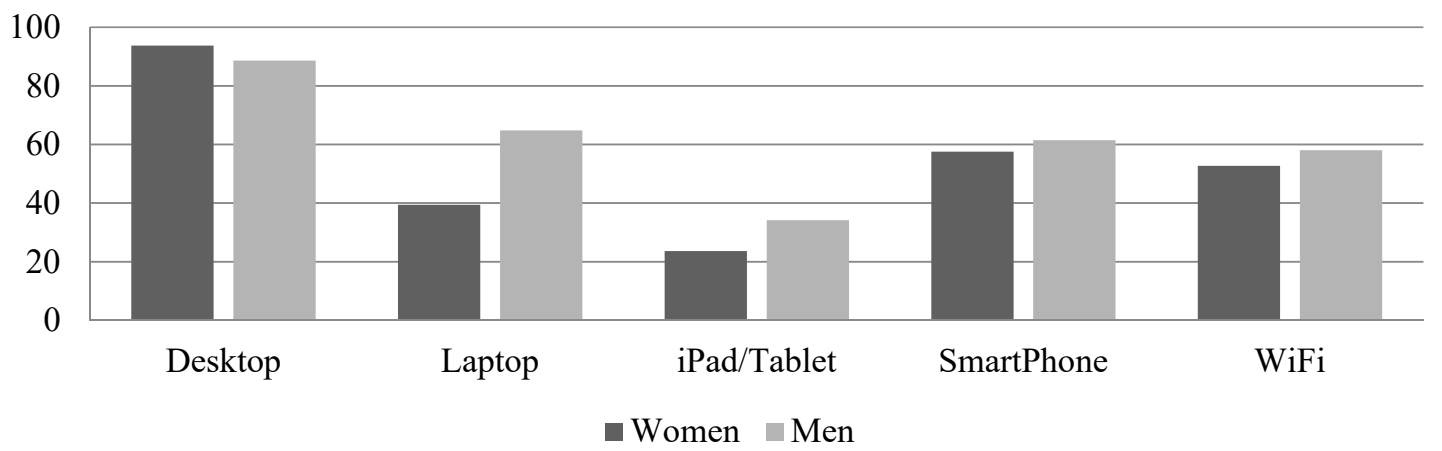

Figure 3. Access to computers and technology.

Figure 4 presents the interaction between the access to technology and gender. When respondents indicated "yes" in response to using a particular device or technology, it was coded as 1; otherwise, a code of 0 was used. The interactions reveal that both men and women have a high level of access to computers and technology. 


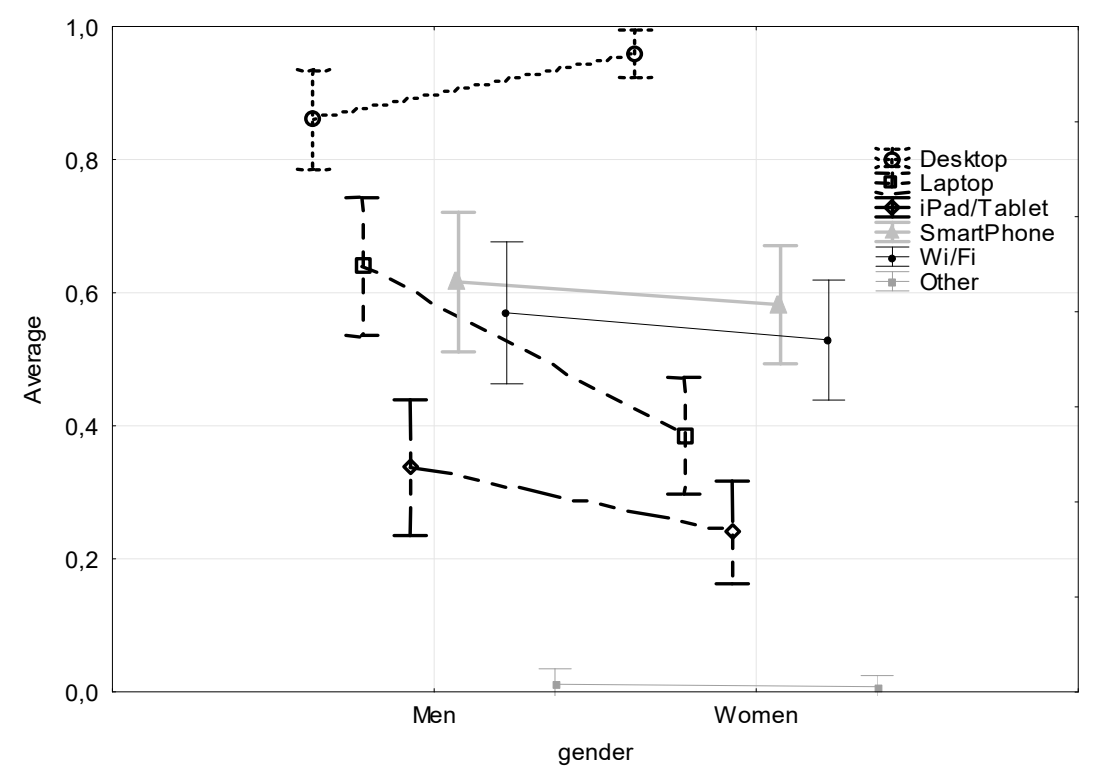

Figure 4. Graph showing the average and confidence interval (1-use; 0 -no access).

Almost all of the respondents ( $97.7 \%$ of the women and $99 \%$ of the men) had used computers technologies for more than five years. Figure 5 reveals how respondents use computers and technologies. Again, usage between men and women was very close for business support, which was at the top. Over $60 \%$ of the respondents from both genders used computer technologies for all areas listed.

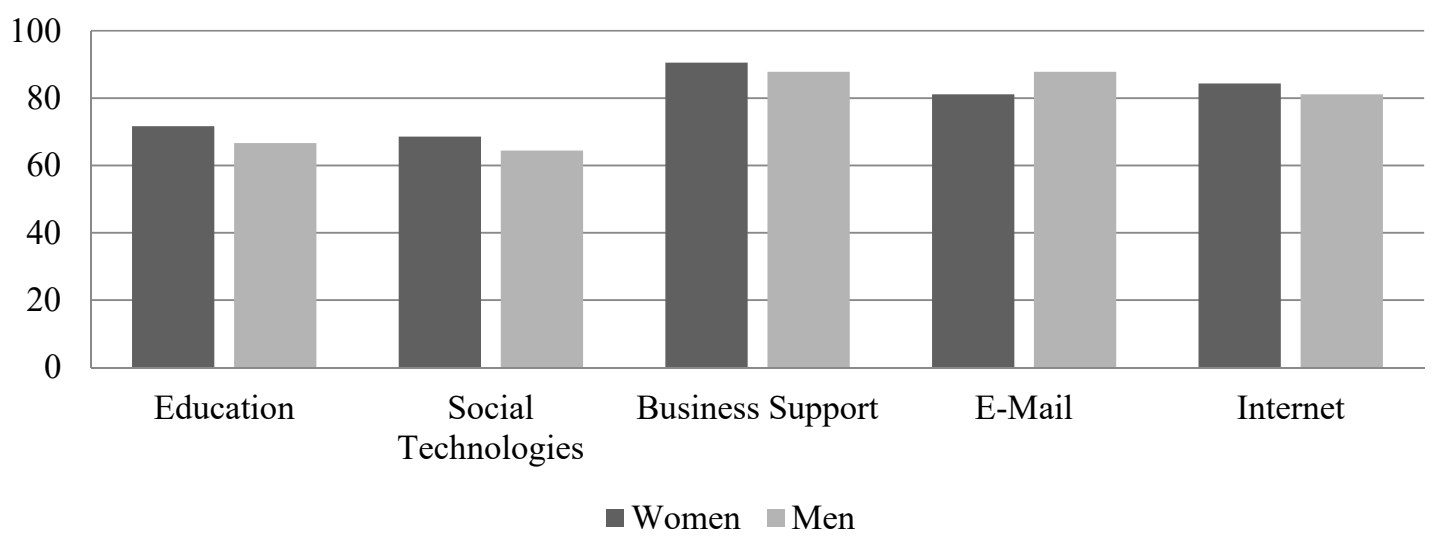

Figure 5. Computer and technology usage.

Table 1 presents the homogeneity of variance according to the $t$-test, Levene's test, and the Brown-Forsythe test. The tests were statistically significant for business support, e-mail, and the internet, meaning the hypothesis of homogeneous variance according to gender should be rejected. Their usage presents a significant variance heterogeneity. For education and social media relating to computer or technology usage, the hypothesis of homogeneous variance could not be rejected.

Table 1. Homogeneity of variances for computer or technology usage.

\begin{tabular}{ccc}
\hline Detailed & $p$-Levene's & $p$-Brown \& Forsythe \\
\hline Use technology in education vs. gender & 0.0000 & 0.0279 \\
Use technology for social media vs. gender & 0.0003 & 0.0596 \\
Use technology for business support vs. gender & 0.0000 & 0.0000 \\
Use technology for e-mail vs. gender & 0.0000 & 0.0000 \\
Use technology for internet vs. gender & 0.0000 & 0.0000 \\
\hline
\end{tabular}


All respondents indicated that they are aware of the benefits technology can provide. When looking at the different areas, as shown in Figure 6, at least two-thirds of women and men found benefits in all areas, with information and communication averaging slightly higher than the others. Social technologies-the main focus of this study—received a "vote of confidence" by $75.6 \%$ of the women and $74.4 \%$ of the mean.

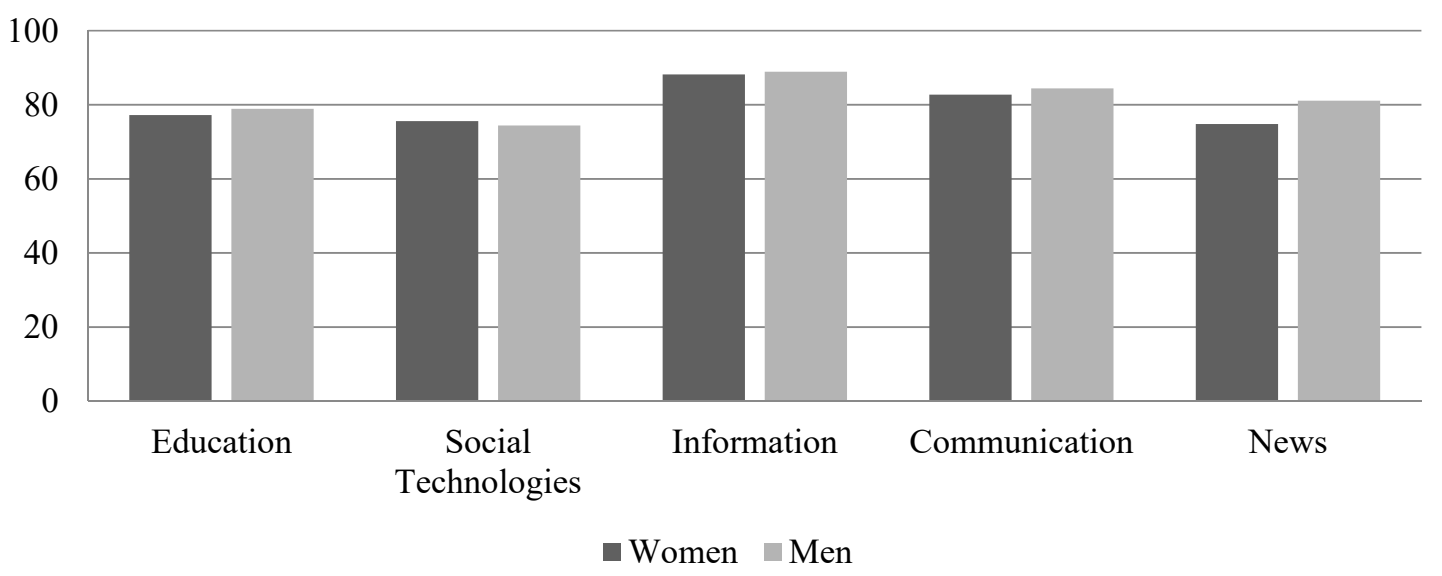

Figure 6. Benefits provided by technology.

To determine the feasibility of social technology platforms in support of empowerment, economic stability, and gender equality, questions were asked of the participants relating to Facebook, Twitter, LinkedIn, YouTube, and Google+ usage.

\subsection{Social Technologies}

Facebook is the largest social technology platform in the world, and as shown in Figure 7 is also the platform used by most Taiwanese female and male respondents. YouTube and Google+ came in second and third, with very minimal numbers (10\%or less) of the respondents using Twitter or LinkedIn.

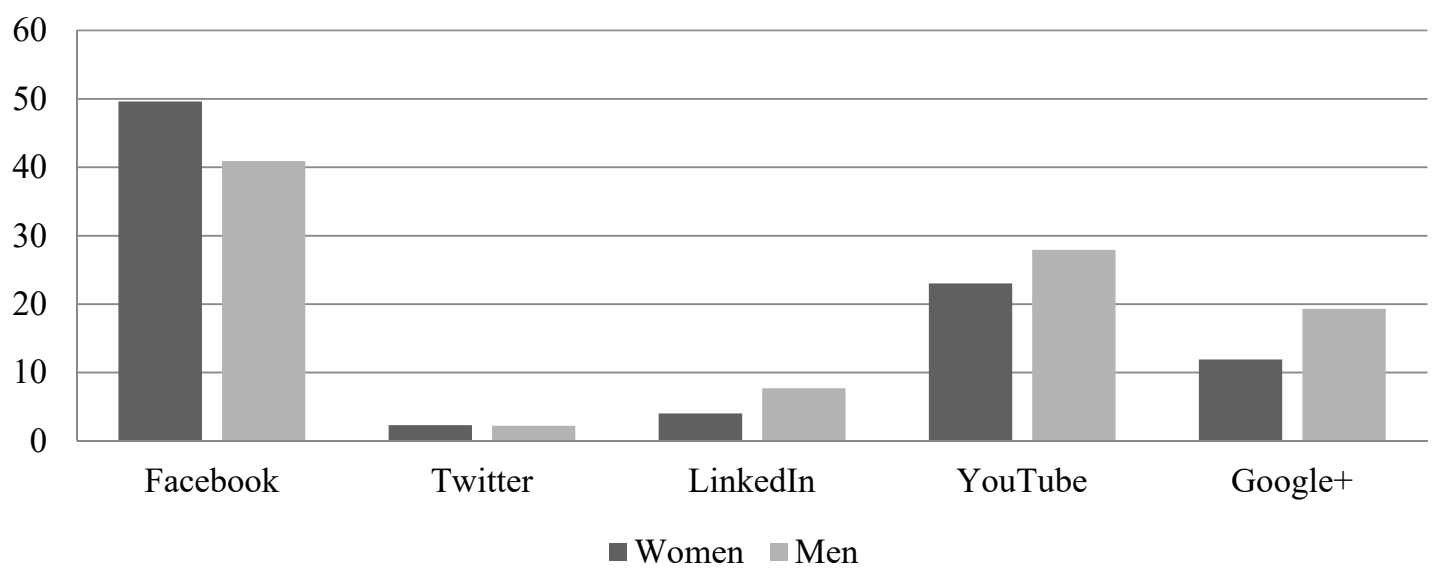

Figure 7. Social technology platforms.

A detailed investigation including purposes of use for each platform and possible benefits was conducted for the study's five platforms. Since Twitter and LinkedIn were checked by less than $10 \%$ of the participants, the results will focus on Facebook, YouTube, and Google+. Purposes listed included communicating or collaborating, customer service, gaining exposure and creating awareness, gaining new customers, increase revenue or profits, marketing, networking, building relationships, and recruiting employees. 


\subsubsection{Facebook}

Table 2 reveals responses regarding purposes for use, and for those who indicated that this platform was used for the stated purpose(s), whether benefits were experienced. Results are statistically presented by gender. A slightly higher percentage of female respondents used Facebook for six of the purposes listed, and a slightly higher percentage of women experienced benefits in these same areas. The two areas where most discrepancies were found were increasing revenue or profits and recruiting employees. Ironically, in these two areas, a higher percentage-by approximately 20 percentage points-of female respondents used Facebook for these two purposes. In comparison, a higher rate of male participants who used Facebook for these two purposes experienced benefits. This may suggest that women in Taiwan have a high awareness of the benefits of social technologies, specifically Facebook, when used for business support and empowerment.

Table 2. Purposes for use and benefits experienced for Facebook.

\begin{tabular}{ccccc}
\hline \multirow{2}{*}{ Detailed } & \multicolumn{2}{c}{ Use for This Purpose } & \multicolumn{2}{c}{ Benefits Experienced } \\
\cline { 2 - 5 } & Women & Men & Women & Men \\
\hline Communicate/Collaborate & 84.5 & 80.5 & 89.3 & 86.2 \\
Customer Service & 86.8 & 80.5 & 92.5 & 82.7 \\
Gain Exposure and Create Awareness & 98.4 & 94.4 & 96.3 & 88.2 \\
Gain New Customers & 82.6 & 80.5 & 86.3 & 86.2 \\
Increase Revenue/Profits & 56.8 & 38.8 & 83.3 & 100 \\
Marketing & 93.5 & 91.6 & 94.3 & 87.9 \\
Network/Build Relationships & 98.4 & 88.8 & 98.1 & 87.5 \\
Recruit Employees & 41.6 & 19.4 & 80.9 & 85.7 \\
\hline
\end{tabular}

\subsubsection{YouTube}

Although fewer respondents used YouTube than Facebook, organizations experienced the benefits of posting video content for business purposes. With this platform, again, there was a higher percentage of women using YouTube for all purposes, however networking or relationship building differed by less than one percentage point, with the rate of male respondents being slightly higher (Table 3). A more significant percentage of women than men experienced benefits in six of the nine areas (two-thirds). The highest percentage of both female and male respondents used YouTube for marketing purposes. Indicating high satisfaction, $100 \%$ of the women using YouTube for marketing and networking or relationship building experienced benefits.

Table 3. Purposes of use and benefits experienced for YouTube.

\begin{tabular}{ccccc}
\hline \multirow{2}{*}{ Detailed } & \multicolumn{2}{c}{ Use for This Purpose } & \multicolumn{2}{c}{ Benefits Experienced } \\
\cline { 2 - 5 } & Women & Men & Women & Men \\
\hline Communicate/Collaborate & 52 & 50 & 83.3 & 66.6 \\
Customer Service & 73 & 62.5 & 88.2 & 73.3 \\
Gain Exposure and Create Awareness & 92.9 & 87.5 & 94.7 & 76.2 \\
Gain New Customers & 55.5 & 54.2 & 69.2 & 76.9 \\
Increase Revenue/Profits & 45.8 & 37.5 & 70 & 77.7 \\
Marketing & 93.3 & 91.7 & 100 & 77.3 \\
Network/Build Relationships & 74.1 & 75 & 100 & 83.3 \\
Recruit Employees & 27.3 & 25 & 50 & 66.6 \\
\hline
\end{tabular}

\subsubsection{Google+}

Although Google+ was in third place for the percentage of social technologies users, the satisfaction rate was the highest, with $100 \%$ of women experiencing benefits from three categories: gaining new customers, increasing revenue or profits, and recruiting employees (Table 4). The male respondents 
expressed an even higher satisfaction rate, with $100 \%$ of the participants indicating benefits experienced in four areas: gaining exposure and creating awareness, gaining new customers, increasing revenue or profits, and recruiting employees.

Table 4. Purposes for use and benefits experienced for Google+.

\begin{tabular}{ccccc}
\hline \multirow{2}{*}{ Detailed } & \multicolumn{2}{c}{ Use for This Purpose } & \multicolumn{2}{c}{ Benefits Experienced } \\
\cline { 2 - 5 } & Women & Men & Women & Men \\
\hline Communicate/Collaborate & 93.3 & 76.4 & 84.6 & 84.6 \\
Customer Service & 86.6 & 52.9 & 77.7 & 77.7 \\
Gain Exposure and Create Awareness & 78.9 & 52.9 & 90.0 & 100 \\
Gain New Customers & 53.3 & 35.3 & 100 & 100 \\
Increase Revenue/Profits & 46.6 & 35.3 & 100 & 100 \\
Marketing & 73.3 & 52.9 & 90.9 & 88.9 \\
Network/Build Relationships & 100 & 82.3 & 66.6 & 85.7 \\
Recruit Employees & 46.6 & 11.8 & 100 & 100 \\
\hline
\end{tabular}

A significantly higher percentage of female respondents than male respondents used Google+ for all purposes listed, with all participants who used Google+ using it for networking or building relationships and with over $90 \%$ of the women using this platform to communicate or collaborate.

Table 5 presents the homogeneity of variance according to Levene's test and the Brown-Forsythe test for Facebook, YouTube, and Google+ usage as reported by respondents. The tests were statistically significant for Facebook and YouTube, meaning the hypothesis of homogeneous variance according to gender should be rejected in this case. Their usage indicates the presence of significant variance of heterogeneity. For Google+ usage, the hypothesis of homogeneous variance could not be dismissed from the gender perspective.

Table 5. Homogeneity of variance for Facebook, YouTube, and Google+ usage.

\begin{tabular}{ccc}
\hline Detailed & $p$-Levene's & $p$-Brown \& Forsythe \\
\hline Facebook vs. gender & 0.0000 & 0.0000 \\
YouTube vs. gender & 0.0000 & 0.0000 \\
Google+ vs. gender & 0.2441 & 0.1361 \\
\hline
\end{tabular}

Respondents were asked about their experiences with social technologies. Many had both positive and negative experiences, but for both women and men the positive experiences far outweighed the negative. $71 \%$ of women and $81 \%$ of men indicated positive experiences, while $43 \%$ of women and $32 \%$ of men had negative experiences. As reported, some respondents indicated both positive and negative experiences when using social technologies in business.

\subsection{Empowerment}

The purpose of this study was not only to determine purposes that the leading social technology platforms are used in Taiwan and whether each provides benefits, but it was important to also look at the results in terms of whether social technologies could empower women in Taiwan and other countries. Over $95 \%$ of the female respondents and $96.3 \%$ of the male participants indicated that they believe education and social technologies could provide empowerment for success.

\section{Discussion}

Social technologies have provided new opportunities for business support and changed the way employees and business owners communicate, provide customer service, gain exposure and create awareness about products or companies, gain new customers, market or brand products and businesses, network and build relationships, and recruit employees. These platforms have made a 
difference to the bottom line for businesses savvy enough to implement social technologies into their strategic plans.

Five of the leading social technology platforms-Facebook, Twitter, YouTube, LinkedIn, and Google+-were included in the study to determine purposes for use and benefits experienced. Most participants used Facebook, YouTube, and Google+, so details about each were included in this paper. All platforms were used for all purposes listed, with benefits experienced for all. However, the percentage of "purposes used" respondents was higher for Facebook users, while the percentages of participants in the "benefits experienced" column was somewhat higher for Google+.

\section{Conclusions}

Overall, a greater percentage of female than male respondents use the various technologies, but the overall differences are perhaps more of a result of the country studied than a world-wide perspective. For example, results may be significantly different in developing countries, coinciding with the results of Moghaddam [25] and Fatehkia et al. [50]. More research is needed, but with the patriarchal system gradually weakening in Taiwan and the gender pay gap being less than in many countries, the results from this study show that the higher use of social technologies by women in the workplace may be an indication of empowerment, leading to narrowing of the gender gap. The differences between women and men using Facebook and YouTube were significant, but not in the case of Google+. Creating new patterns and social interactions empowers men and women to be more creative and to increase their business opportunities [51].

The findings from this study apply to the Taiwanese respondents specifically, but can be used to help empower women across the world. Women must take responsibility to use the tools and information from studies such as this to find their voice, create a network, and help others enjoy empowerment, success, and economic equality. The study results could be beneficial in areas of the on-going discussion regarding psychological attitudes to social media platforms and their roles, as well as gender differences in social and digital media interactions [43].

Digital technologies can support female empowerment, and these studies provide evidence that social media platforms such as Facebook and Twitter are used in a broad way by women, for tasks such as creating awareness, marketing, or building relationships. Women also experience benefits from using these digital technologies at almost the same level as men; however, education was deemed to be a key factor for success in this area.

The limitations of the study include the number of respondents and the limited geographic area. Expanding the response rate and global results would further validate these results, making it generalizable to a worldwide population and allowing for a comparison among countries. Future research should study: (1) the impact of training and education on users' awareness of using social media; (2) security and data protection for knowledge on the Internet; and (3) additional variables of success that may influence users' empowerment.

Author Contributions: Conceptualization, J.H.N. and J.P.; methodology, M.M.-S.; validation and data collection, T.-R.L.; formal analysis, M.M.-S.; writing—original draft preparation, J.H.N., J.P., and M.M.-S.; writing-review and editing, J.H.N., J.P., M.M.-S. All authors have read and agreed to the published version of the manuscript

Funding: This research received no external funding.

Acknowledgments: We would like to thank all the responders who participated in this study.

Conflicts of Interest: The authors declare no conflict of interest.

\section{References}

1. Cascio, W.F.; Montealegre, R. How Technology Is Changing Work and Organizations. Annu. Rev. Organ. Psychol. Organ. Behav. 2016, 3, 349-375. [CrossRef] 
2. Haddud, A.; Dugger, J.C.; Gill, P. Social Media for Organizations Exploring the Impact of Internal Social Media Usage on Employee Engagement Journal of Social Media for Organizations Exploring the Impact of Internal Social Media Usage on Employee Engagement. J. Soc. Media Organ. 2016, 3, 1.

3. Subramanian, K.R. Technology and Transformation in Communication. J. Adv. Res. Electr. Electron. Eng. 2018, 5, 1-13.

4. Cairo, A. Managing employees in a social media technology workplace. N. Z. Manag. 2014, 61, 21.

5. Paliszkiewicz, J.; Koohang, A. Social Media and Trust: A Multinational Study of University Students; Informing Science Press: Santa Rosa, CA, USA, 2016.

6. Logan, R.K. Understanding humans: The extensions of digital media. Information 2019, 10, 304. [CrossRef]

7. Nicholas, D.; Rowlands, I. Social media use in the research workflow. Inf. Serv. Use 2011, 31, 61-83. [CrossRef]

8. Mital, M.; Sarkar, S. Multihoming behavior of users in social networking web sites: A theoretical model. Inf. Technol. People 2011, 24, 378-392. [CrossRef]

9. Merchant, G. Unravelling the social network: Theory and research. Learn. Media Technol. 2012, 37, 4-19. [CrossRef]

10. Chou, C.M. Social media characteristics, customer relationship and brand equity. Am. J. Bus. 2019, 10, 128-139.

11. Ngai, E.W.T.; Moon, K.K.; Lam, S.S.; Chin, E.S.; Tao, S.S. Social media models, technologies, and applications: An academic review and case study. Ind. Manag. Data Syst. 2015, 115, 769-802. [CrossRef]

12. Lin, S.F.; Lin, C.L.; Lee, D.C. The relationship between elementary school teachers' technology readiness and intention to use social media platforms for classroom management. Int. J. Organ. Innov. 2015, 8, 48-63.

13. Selwyn, N.; Stirling, E. Social media and education ... now the dust has settled. Learn. Media Technol. 2016, 41, 1-5. [CrossRef]

14. Greenwood, D. Local Indicators of Quality of Life: A Preliminary Look at the Pikes Peak Region; University of Colorado at Colorado Springs, Center for Colorado Policy Studies: Denver, CO, USA, 2001; pp. 1-29.

15. Hjorth, L.; Hinton, S. Understanding Social Media; SAGE: London, UK, 2019.

16. Nord, J.H.; Paliszkiewicz, J.; Koohang, A. Using social technologies for competitive advantage: Impact on organizations and higher education. J. Comput. Inf. Syst. 2014, 55, 92-104. [CrossRef]

17. Gholipour, A.; Rahimian, A.; Mirzamani, A.; Zehtabi, M. IMPACT Model of Women's Empowerment. Int. Bus. Res. 2010, 3, 57-65. [CrossRef]

18. Cornwall, A.; Anyidoho, N.A. Introduction: Women's empowerment: Contentions and contestations. Development 2010, 53, 144-149. [CrossRef]

19. Lin, J.; Nord, J.H.; Paliszkiewicz, J.; Maadra-Sawicka, M. China' s social networks: Culture, business, and the gender gap. J. Asia Entrep. Sustain. 2017, 13, 132-175.

20. Nord, J.H.; Achituv, D.B.; Paliszkiewicz, J. Communication through Social Technologies: A Study of Israeli Women. J. Int. Technol. Inf. Manag. 2017, 26, 45-80.

21. Amichai-Hamburger, Y.; Vinitzky, G. Social network use and personality. Comput. Hum. Behav. 2010, 26, 1289-1295. [CrossRef]

22. Muscanell, N.L.; Guadagno, R.E. Make new friends or keep the old: Gender and personality differences in social networking use. Comput. Hum. Behav. 2012, 28, 107-112. [CrossRef]

23. Pagani, M.; Hofacker, C.F.; Goldsmith, R.E. The Influence of Personality on Active and Passive Use of Social Networking Sites. Psychol. Mark. 2011, 28, 441-456. [CrossRef]

24. Caison, A.; Bulman, D.; Pai, S.; Neville, D. Exploring the technology readiness of nursing and medical students at a Canadian University. J. Interprof. Care 2008, 22, 283-294. [CrossRef] [PubMed]

25. Moghaddam, G.G. Information technology and gender gap: Toward a global view. Electron. Libr. 2010, 28, 722-733. [CrossRef]

26. Lin, C.H.; Yu, S.F. Adolescent internet usage in Taiwan: Exploring gender differences. Adolescence 2008, 43, 317-331. [PubMed]

27. Raffaelli, M.; Ontai, L.L. Gender socialization in latino/a families: Results from two retrospective studies. Sex Roles 2004, 50, 287-299. [CrossRef]

28. Hong, Z.R.; Veach, P.M.C.; Lawrenz, F. An investigation of the gender stereotyped thinking of Taiwanese Secondary School boys and girls. Sex Roles 2003, 48, 495-504. [CrossRef]

29. Hong, Z.R. An investigation of Taiwanese female college students' sexist attitudes. Sex Roles 2004, 51, 455-467. [CrossRef] 
30. Aslanbeigui, N.; Pressman, S.; Summerfield, G. Toward gender equity: Policies and strategies. Int. J. Polit. Cult. Soc. 2003, 16, 327-330. [CrossRef]

31. Geo-JaJa, M.A.; Paynem, S.J.; Hallam, P.R.; Baum, D.R. Gender equity and women empowerment in Africa: The education and economic globalization nexus. In Race, Ethnicity and Gender in Education; Springer: Dordrecht, The Netherlands, 2009; Volume 6, pp. 97-121.

32. Marzano, G.; Lubkina, V. The Digital Gender Divide: An Overview. In Proceedings of the 2019 International Scientific Conference Society, Integration, Education, Rezekne, Latvia, 24-25 May 2019; Volume 5, pp. 413-421.

33. Lin, C.I.; Tang, W.H.; Kuo, F.Y. Mommy wants to learn the computer': How middle-aged and elderly women in Taiwan learn ICT through social support. Adult Educ. Q. 2012, 62, 73-90. [CrossRef]

34. Chin, J. No improvement in gender pay gap: Labor ministry. Taipei Times, 16 March 2018.

35. World Economic Forum. Global Gender Gap Report 2020; World Economic Forum: Geneva, Switzerland, 2020.

36. Ibrahim, S.; Alkire, S. Agency and empowerment: A proposal for internationally comparable indicators. Oxf. Dev. Stud. 2007, 35, 379-403. [CrossRef]

37. Poddar, K.K. Role of Self Help Groups in Economic Empowerment of Women in India. Anusandhanika 2013, 5, 237-241.

38. Kabeer, N. Resources, Agency, Achievements: Reflections on the Measurement of Women's Empowerment. Dev. Chang. 1999, 30, 435-464. [CrossRef]

39. Wallerstein, N.; Bernstein, E. Empowerment Education: Freire's Ideas Adapted to Health Education. Health Educ. Behav. 1988, 15, 379-394. [CrossRef] [PubMed]

40. Rappaport, J. Studies in empowerment: Introduction to the issue. Prev. Hum. Serv. 1984, 3, 1-7. [CrossRef]

41. Gibson, C.H. A concept analysis of empowerment. J. Adv. Nurs. 1991, 16, 354-361. [CrossRef]

42. Simsek, M. Being a Woman in Turkey: An Application. Econ. Manag. Financ. Mark. 2014, 9, 419-428.

43. Mason, K.O.; Smith, H.L. Women's Empowerment and Social Context: Results from Five Asian Countries. 2003. Available online: https://pdfs.semanticscholar.org/6d1a/8d3e0d704c1ae15d78b1d957a6bb4ff98fac.pdf (accessed on 17 April 2020).

44. Hsu, W.S. The facets of empowerment in solution-focused brief therapy for lower-status married women in Taiwan: An exploratory study. Women Ther. 2009, 32, 338-360. [CrossRef]

45. Xie, I.; Stevenson, J. Social media application in digital libraries. Online Inf. Rev. 2014, 38, 502-523. [CrossRef]

46. Kaplan, A.M.; Haenlein, M. Users of the world, unite! The challenges and opportunities of Social Media. Bus. Horiz. 2010, 53, 59-68. [CrossRef]

47. Steenkamp, M.; Hyde-Clarke, N. The use of Facebook for political commentary in South Africa. Telemat. Inform. 2014, 31, 91-97. [CrossRef]

48. Safko, L.; Brake, D.K. The Social Media Bible: Tactics, Tools and Strategies for Business Success; John Wiley \& Sons Ltd.: Hoboken, NJ, USA, 2009.

49. Koohang, A.; Paliszkiewicz, J.; Nord, J.H. Social media privacy concerns among college students. Issues Inf. Syst. 2018, 19, 11-19.

50. Fatehkia, M.; Kashyap, R.; Weber, I. Using Facebook ad data to track the global digital gender gap. World Dev. 2018, 107, 189-209. [CrossRef]

51. Cha, M.; Kwak, H.; Rodriguez, P.; Ahn, Y.Y.; Moon, S. I tube, you tube, everybody tubes: Analyzing the world's largest user generated content video system. In Proceedings of the 7th ACM SIGCOMM Conference on Internet Measurement, San Diego, CA, USA, 24-26 October 2007; Association for Computing Machinery: New York, NY, USA, 2007; pp. 1-14.

(C) 2020 by the authors. Licensee MDPI, Basel, Switzerland. This article is an open access article distributed under the terms and conditions of the Creative Commons Attribution (CC BY) license (http://creativecommons.org/licenses/by/4.0/). 